\title{
Subtitling and the promotion of multilingualism: the case of marginalised languages in South Africa
}

\author{
Jan-Louis Kruger, Haidee Kruger and Marlene Verhoef \\ North-West University (Vaal Triangle Campus)
}

This article investigates the role that subtitling may play in the promotion of multilingualism in South Africa. After a reflection on the current language-political situation in the country, in particular as it pertains to the public broadcaster, the findings of a pilot study focusing on the role of subtitling in promoting multilingualism and language rights in South Africa are presented. The research involves aspects such as language status, attitudes and acquisition, focusing on two of the more marginalised languages in the country, namely Tshivenda and Xitsonga. It also touches on the impact of subtitling on comprehension.

\section{Introduction: multilingualism in South Africa}

Questions of language are basically questions of power. Noam Chomsky (1979: 191)

The Constitution of South Africa protects the language rights of all South Africans, awarding official status to eleven languages which "must enjoy parity of esteem and must be treated equitably" (South Africa 1996: 6(4)). In addition, the Constitution clearly states the following: "Recognising the historically diminished use and status of the indigenous languages of our people, the state must take practical and positive measures to elevate the status and advance the use of these languages" (ibid.: 6(1)).

In South Africa, the concept of language rights, or linguistic human rights, is closely tied to the concept of multilingualism. In order to respect the language rights of all South Africans, multilingualism needs to be protected constitutionally, but this protection needs to filter through all sectors of society, as a commitment to respect and involve all languages relevant to a particular community, and to take active measures to elevate the status and advance the use of indigenous languages. Erasmus (2002: 198) makes this point very succinctly: "The recognition and development of all South Africa's languages is in fact not merely a status quo to be maintained, but an objective towards which all citizens of the country should strive."

Despite its worthy intentions, the degree to which the state has managed to attain its objectives regarding language rights as set out in the Constitution is debatable. It is the view of Erasmus (ibid.) and other sociolinguists that a process of Anglicisation is currently being implemented by the state on the pretext of financial constraints and practical viability. Even 
if one does not agree with the opinion that this is a calculated, deliberate process, initiated and sustained by the government, one certainly has to acknowledge the prevalence of what May (2004: 35) calls "resigned language realism" - an acknowledgement that the process of language shifts and loss is inevitable and powerful, and that majority languages (like English) are the most instrumentally useful, allowing their speakers social mobility and economic progress (Durgunoğlu \& Verhoeven 1998: 292; May 2004: 41). In South Africa, specifically, this means the increasing prevalence of English for all modes of communication, based on the perception (prevalent also among people who do not speak English as a first language) that social, cultural and economic advancement is inextricably linked to proficiency in English. Barnett (2000: 68) emphasises the symbolic and pragmatic power of English, which is likely to continue to grow in future (thereby potentially undermining political commitments to linguistic diversity).

However, hopes for English as a lingua franca for all South Africans are curbed by realities such as illiteracy and lack of access to education (ibid.: 65). This is confirmed by the results of a sociolinguistic survey (PanSALB 2001) which seem

to illustrate the fallacy of assuming that a lingua franca exists in South Africa. Some language groups contain very few people who understand Afrikaans. Some include very few people who understand English. The proportions that understand other African languages vary from less than $10 \%$ among some groups to around $40 \%$, but seldom more. Clearly South Africans need a more inclusive language policy than one based on the assumption that one language has sufficient reach to be an adequate medium of communication across the country (ibid.: 11).

In addition, there are ideological issues at play. Webb (1996) discusses the politicisation of language in the South African context at length, pointing out that the politicised language situation in South Africa has had effects on the educational, social, political, cultural and economic domains. English is, and will in all likelihood remain, the most important language of communication internationally. In South Africa, as Webb (ibid.: 145) points out, English has an exceptionally high status. It is not only regarded as the major economic, educational, and social language, but has also become a symbol of the struggle against apartheid, and of liberation. However, English is also a colonial language, and its dominance as a language of wider communication, coupled with the fact that it is truly accessible only to a privileged minority, poses "a very real psycholinguistic threat of alienation" (Erasmus 2002: 200). Even if one questions the unproblematised, often essentialist link between language and (personal and communal) identity (see May 2004: 38-40 for such criticism), it is undeniable that particular languages clearly are for many people an important and constitutive factor of their individual, and at times, collective identities. In theory, then, language may 
well be just one of many markers of identity. In practice, it is often much more than that. Indeed, this should not surprise us since the link between language and identity encompasses significant cultural and political dimensions.

The promotion of multilingualism in South Africa therefore seems to be in a double bind. Promoting English as "majority language" will inevitably lead to the marginalisation of the indigenous languages, whereas encouraging speakers of indigenous languages to insist on their right to speak, read, hear and learn in their own language in all contexts may be construed as delimiting or ghettoising such speakers within the confines of a language that does not have a wider use and constrains social mobility (ibid.: 41). However, perhaps this oppositional approach to the situation is unnecessary. Could we not acknowledge and promote the instrumental value of English, and the mobility and utility it offers, while simultaneously acknowledging and promoting the value, status, utility and mobility of the indigenous languages, thereby contributing to a truly multilingual society? As May (ibid.: 46) points out:

[t]he limited instrumentality of particular minority languages at any given time need not always remain so. Indeed, if the minority position of a language is the specific product of wider historical and contemporary social and political relationships, changing these wider relationships positively with respect to a minority language should bring about both enhanced instrumentality for the language in question, and increased mobility for its speakers.

In this respect, the government's involvement in language policy and language planning is crucial.

In this article, attention is given to one domain in which the state may play a vast role in promoting multilingualism, namely broadcasting, and particularly television broadcasting by the national broadcaster, the South African Broadcasting Corporation (SABC). The article first provides an overview of some salient issues surrounding multilingualism, language rights, language planning, broadcasting and subtitling in South Africa. This is followed by a discussion of a pilot study conducted in 2005 on the potential role of subtitling in developing marginalised languages and promoting multilingualism. Primarily, we wished to determine, by means of an empirical study ${ }^{1}$, whether the introduction of subtitles in marginalised indigenous languages could contribute to the (perceived) symbolic and instrumental value of functional multilingualism. ${ }^{2}$ If so, subtitling has the potential to be used to great effect in the multi-functional development of particularly the minority languages, but also the other indigenous languages. Furthermore, subtitling into the regional languages of South Africa could enhance the comprehension of English television programmes. This is important not only for recreational purposes, but, more crucially, to empower people by means of improving their access to information. Subtitling could therefore 
potentially play a crucial role in the acknowledgement of the language rights of all South Africans. ${ }^{3}$

\section{Multilingualism, language rights and language planning}

The following distinction among the three types of fundamental language rights made by Sachs (1994: 110) is of particular importance for this study:

- $\quad$ the right to use your language;

- $\quad$ the right to develop your language;

- $\quad$ the right to be understood and to understand other languages. ${ }^{4}$

These language rights, as also reflected in the Constitution, are based on the acknowledgement that "the recognition of linguistic human rights is a prerequisite for the development of communities. Through language, access to resources, such as political and economic power, is controlled" (Erasmus 2002: 199). Webb (1996: 146) also emphasises this link, pointing out that language is a source of community development, which gives access to education, economic opportunities, political participation, social mobility and cultural activity. The Harare Declaration, the result of the Intergovernmental Conference of Ministers on Language Policy in Africa, (20-21 March 1997) similarly states that "the optimal use of African languages is a prerequisite for maximising African creativity and resourcefulness in development activities" (Harare Declaration 1997).

A logical deduction from the above is that language loss "is not only, perhaps not even primarily, a linguistic issue - it has much more to do with power, prejudice, (unequal) competition and, in many cases, overt discrimination and subordination" (May 2004: 37). Against this background the importance of clear language planning and policies is obvious. The Harare Declaration also emphasises the importance of language planning and the adoption of clear policies for the use and development of all languages spoken in Africa, particularly mother tongues and community languages (Harare Declaration 1997). The protection of minority languages, or marginalised languages, is therefore of particular importance, as linguistic marginalisation almost always corresponds to social, cultural and political marginalisation (May 2004: 38). Therefore, "linguistic human rights advocates argue that minority languages, and their speakers, should be accorded at least some of the protections and institutional support that majority languages already enjoy" (ibid.:: 38) - most tangibly reflected in governmental language policy and planning.

Language planning is essentially "a sustained and conscious effort to alter a language itself, or to change its function in a society for the purpose of solving communication problems" (Verhoeven \& Durgunoğlu 1998: xiv). According to Cooper (1989) language planning as activity and research focus entails corpus planning, status planning and acquisition 
planning. Corpus planning involves aspects such as the harmonisation of related languages and the creation and/or standardisation of words in the translation process. Acquisition planning entails expanding the uses of a particular language through an increase in language proficiency and literacy. Status planning refers to the expansion of language functions, and changing people's attitude towards their language. Webb (1996: 146) makes clear that the resource value of a language depends on its corpus development, its status and the degree to which it is known in the community. Therefore, in any investigation of the promotion of multilingualism, each of these aspects needs to be addressed. The pilot study of which the results are presented in this article proceeded from the assumption that subtitling has the potential to contribute to all three these fields of language planning.

According to Verhoeven and Durgunoğlu (1998: xiv), language policies manifest themselves primarily in two domains: the mass media and education. In the following section, the attention turns specifically to the television broadcasting situation in South Africa, focusing on the language policy and practice of the SABC as public broadcaster.

\section{The current television broadcasting situation in South Africa}

The SABC's mandate as national broadcaster emphasises its objective of providing a wide range of programming in all the official languages, reflecting "South Africa's diverse languages, cultures, provinces and people in its programmes" (SABC 2005: 1). This commitment is further set out in the broadcaster's language policy:

Owing to its virtually universal accessibility and use, the public broadcaster has a unique responsibility to broadcast programmes that promote development of national identity while supporting development of our languages and cultures. South Africa, and consequently the public broadcaster, is faced with a further challenge: that of bringing marginalised national languages, cultures and identities into the mainstream (ibid.: 1).

In view of this, the SABC (ibid.: 2) states that its aims and objectives are to:

- inform, educate and entertain South Africans in their home languages;

- $\quad$ promote understanding and acceptance of and between the linguistic and cultural groups in South Africa;

- $\quad$ contribute to the continual development of the 11 official languages and South African sign languages;

- $\quad$ promote multilingualism in South Africa. 
In its policy document, the SABC sets out a number of steps to do so, including the "[a]pplication of appropriate technologies to achieve language coverage and access goals" (ibid.: 3 ). It continues to say: "We strive to explore the use of technologies such as subtitling to ensure that programmes are accessible to as many viewers as possible. At times this objective is met the best by broadcasting in cognate or widely understood languages." (ibid.: $5)$.

Despite this aim, the relatively little subtitling on the SABC channels attests to the lack of commitment on the SABC's part in this regard. Also, the fact that subtitling is only done into English, suggests the SABC's promotion of English at the expense of the indigenous languages.

In the past two years the $\mathrm{SABC}$ has increased the number of programmes in indigenous languages on $\mathrm{SABC} 1$ and $\mathrm{SABC} 2 . \mathrm{SABC} 3$ is mostly (more than 95\%) English. The increase in the number of programmes in indigenous languages is probably at least partially due to the language quotas prescribed by the Independent Communications Authority of South Africa (ICASA) in its 2005 licensing conditions to the broadcaster:

- $\quad$ SABC1: A minimum of $50 \%$ of all prime-time programming in Nguni languages by $2007 ; 65 \%$ by $2011-12$.

- $\quad$ SABC2: A minimum of $65 \%$ of broadcasts in languages other than English by 2005-06; 70\% by 2008-09 (Allafrica.com 2005).

In $2006,57 \%$ of prime-time programming on $\mathrm{SABC} 2$ was in languages other than English. On SABC1 $45 \%$ of prime-time programming was in languages other than English, while on SABC3 only 3\% of programming was not in English (SABC 2006).

The use of subtitling on the three SABC channels has increased significantly over the past two years. While no official data could be found regarding the percentage of subtitled programmes on $\mathrm{SABC}$, an informal two-week survey in May 2006 suggested that approximately 25\% of primetime programming on $\mathrm{SABC} 1$, and $21 \%$ on $\mathrm{SABC} 2$ is subtitled. However, subtitling is almost exclusively into English. This effectively means that $80 \%$ of prime-time programming on $\mathrm{SABC} 1,60 \%$ on $\mathrm{SABC} 2$, and virtually all prime-time programming on $\mathrm{SABC} 3$ are accessible to viewers who understand English.

The population numbers of the various language groups in South Africa are presented in Table 1. 
Table 1: Language distribution in South Africa (Statistics South Africa 2003)

\begin{tabular}{|l|l|l|}
\hline Language & Number of speakers & Percentage \\
\hline IsiZulu & 10677305 & 23.8 \\
\hline IsiXhosa & 7907153 & 17.6 \\
\hline Afrikaans & 5983426 & 13.3 \\
\hline Sepedi & 4208980 & 9.4 \\
\hline Setswana & 3677016 & 8.2 \\
\hline English & 3673203 & 8.2 \\
\hline Sesotho & 3555186 & 7.9 \\
\hline Xitsonga & 1992207 & 4.4 \\
\hline Siswati & 1194430 & 2.7 \\
\hline Tshivenda & 1021757 & 2.3 \\
\hline IsiNdebele & 711821 & 1.6 \\
\hline Other & 217293 & 0.5 \\
\hline Total & $\mathbf{4 4 8 1 9 7 7 8}$ & $\mathbf{1 0 0}$ \\
\hline
\end{tabular}

Mother-tongue speakers of English constitute only 8\% of the total population. While the perception is that the majority of the South African population is proficient in English, a sociolinguistic survey (PanSALB 2001: 9) has indicated that only $22 \%$ of non-English-speaking South Africans feel they are fully proficient in English to the degree that allows them full access to speeches and statements in English, while 27\% feel that they understand only as much as they need to. According to the report on this survey, "[t]he results suggest that communication of political, policy and administrative information in South Africa is generally only adequately understood by half the non-English-speaking population". This makes the predominance of English on the SABC difficult to defend.

ICASA, in its rulings on language content on the different broadcasters, stipulates that "programming that contain subtitles in the required language would not be counted towards the language quotas per station" (Media Monitoring Project 2005: 43). Perhaps the fear is that broadcasters would opt for subtitling foreign programmes at the expense of producing local programmes. Ironically, this ruling takes away any incentive for the $\mathrm{SABC}$ to provide subtitling in indigenous languages. This is a great pity in terms of the development and status of indigenous languages.

The SABC's official language policy as well as ICASA's rulings have great potential to be positive interventions in terms of the development and promotion of multilingualism in South Africa, but unfortunately both these institutions also, to some degree, make negative interventions. ICASA's stipulation that subtitling, unlike dubbing, does not count towards language quotas takes away a possible incentive to utilise the mode more effectively in all official languages, and also for the Deaf and hard of hearing. Similarly, the SABC's unofficial policy of subtitling only into English 
denies the other official languages a valuable opportunity to raise their status.

The preference for English at the expense of any of the other official languages can be interpreted as an encroachment on the language rights of all other language communities served by the SABC as public broadcaster. The Media Institute of Southern Africa's South African chapter (MISA-SA) has commented on the SABC's "non-committal stance" in terms of the execution of its language policy. It is the opinion of MISA-SA that the SABC's language policy (not necessarily in principle, but definitely in practice) undermines the equitable treatment of all languages, as expressed in the Constitution and section 6 of the Broadcasting Act, $n^{\circ} 4$ of 1999, as amended (MISA-SA 2003).

Erasmus (2002: 201) summarises the key question surrounding the viability of multilingualism as follows: "Is multilingualism an affordable, practicable, viable option in a Third World environment?" Financial viability and practical considerations are indeed most often cited as reasons for an unwillingness to implement a greater degree of multilingualism. According to Joubert (1999: 11) the lack of multilingualism at the SABC is the inevitable result of financial constraints. The SABC (2002) itself agrees and notes that it is simply too expensive and impractical to give all South African language communities equitable airtime. It is at this juncture that our current research aims to intervene by providing evidence that subtitling, as a relatively cheap aid, can go a long way towards promoting multilingualism on SABC television and in the broader South African community.

\section{Subtitling and multilingualism}

Erasmus (2002: 198) observes that "[f]inding creative ways of circumventing the institutional resistance to the transformation of past bilingual practices is [...] of paramount importance". Certainly, South Africa's unique situation calls for unique, creative problem solving.

Subtitling has a great deal of potential as one such creative solution to the promotion of multilingualism on the national broadcaster, and is in line with the SABC's principle of applying "appropriate technologies to achieve language coverage and access goals" (SABC 2005: 5). Nevertheless, subtitling remains largely underutilised.

One has to concede that subtitling is a constrained mode of translation. A subtitler has to juggle line length, line breaks, audio signals, visual signals, shot changes, scene changes, visual and aural rhythm, and, perhaps most importantly, reading speed or subtitle duration in addition to considerations related to audience needs. And unlike in literary translation, the subtitler can seldom afford him-/herself the luxury of overt translation. The subtitler has to strive to be invisible. The reason for this is simple: unlike the translation of a novel or an operating manual, subtitles are an aid for an audience that would otherwise not have had access to the audiovisual text - 
either because they do not understand the language or because they cannot hear the language. As such, subtitling is more akin to interpreting where the interpreter and the audience are aware of the simultaneous (or recent) existence of the source utterance.

While the audience is therefore being made aware of the fact that the subtitles are a translation of the soundtrack (and other relevant signals), they do not want to be forced to read the text at the expense of the other semiotic layers. Any failure to comply with certain technical or linguistic requirements therefore takes the attention of the viewer away from the screen, effectively obscuring or detracting from the primary text.

In spite of these technical constraints of the mode, subtitling offers the unique benefit in terms of multilingualism that more than one language is available. In the South African context this is used to great effect by subtitling multilingual programmes into English, thereby providing a single written code for a number of alternating spoken codes.

This benefit could be made even more effective in terms of multilingualism by providing subtitling in all the official languages, and particularly in the marginalised languages, thereby contributing to the realisation of Sachs's (1994: 110) three types of language rights. The mere presence of a language in writing on screen also elevates the status of that language while fulfilling the indirect function of expanding higher-order language functions and reinforcing linguistic conventions towards standardisation in that language.

The following section provides an overview of the pilot study undertaken during 2005 to investigate the potential impact of subtitling into languages other than English in South Africa, specifically in terms of language status and multilingualism.

\section{Research}

\subsection{Background}

The pilot study focused on two marginalised official languages, Tshivenda and Xitsonga. The reason for the marginalised status of these languages is attributable not only to the fact that they are each spoken by less than 5\% of the total population, but also to the fact that they are spoken mainly in remote rural areas. Furthermore, they do not belong to either of the two major language families, namely the Nguni languages (IsiZulu, IsiXhosa, IsiNdebele and Siswati) and the Sotho languages (Sesotho, Setswana and Sepedi).

Barnett (2000: 77) points out that especially the minority African languages have not received a great deal of attention in broadcasting debates, compared to, for example, Afrikaans. The Afrikaans language lobby is backed by strong organisational and economic resources. Barnett (ibid.: 77) continues to say: 
Supporters of the development of African languages cannot mobilise the same sort of economic resources for the development of African-language media services. Both the political representation on behalf of these languages and the provision of broadcasting services in them are much more dependent on the different agencies of the state than is the case for either English or Afrikaans, given the greater effective market power and independent institutional resources available to speakers of these two languages.

The promotion of multilingualism in South Africa concerns the expansion of language functions by developing the higher-order functions of all the African languages, and particularly the marginalised languages. The pilot study focused primarily on issues related to status and acquisition planning, partially because of the extreme marginalisation of the languages involved, and partially because the attitude of a language community forms the foundation of language planning.

Language acquisition is an important consideration in multilingualism from the perspective of any individual language, and particularly the smaller and most marginalised languages in any community, because it entails an expansion in the use of the language. This is crucial in the case of languages that are mainly limited to spoken functions. There are, for example, no newspapers in any of the marginalised languages in South Africa. On television, Tshivenda viewers have access to one multilingual drama series per week in which Tshivenda is represented, one multilingual magazine programme containing Tshivenda, and one ten-minute news bulletin. Xitsonga viewers receive only a ten-minute news bulletin per day and limited representation in a couple of multilingual programmes.

Viewers in any of these languages consequently seldom get the opportunity to read their own language. We set out to determine whether the possibility of reading their own language in the form of subtitles would have any impact on the way these groups perceive the expansion in use of their language. Similarly, we set out to test the hypothesis that subtitles have the potential to impact on language status by affecting people's attitude towards their language. We also investigated the potential of subtitles to improve the comprehension of audiovisual material.

\subsection{Experimental design}

In order to determine the above, we visited rural communities of Tshivenda and Xitsonga speakers. We had to be content with an availability sample (a total of 62 respondents), sometimes consisting exclusively of women. In each case we divided the language group into three subgroups.

Firstly, respondents completed an individual biographical and attitudinal questionnaire. Each group was then shown an episode of a multilingual local edudrama, Soul City, dealing with HIV/Aids. One subgroup saw the video without subtitles (Tshivenda: $n=10$; Xitsonga: $n=10$ ), one with 
English subtitles (Tshivenda: $\mathrm{n}=11$; Xitsonga: $\mathrm{n}=10$ ), and one with subtitles in their mother tongue (Tshivenda: $\mathrm{n}=11$; Xitsonga: $\mathrm{n}=10$ ). This was followed by an individual comprehension questionnaire on the content of the video. The session was concluded with a focus-group discussion during which comprehension and attitudes were investigated.

Due to the fact that this was a pilot study, it was decided to make use of the qualitative survey method, also because the data yielded by this type of research method is more useful for personalised feedback to determine attitudes and trends. It is anticipated that studies following from this research will involve both qualitative and quantitative surveys.

\subsection{Results}

The attitudinal questionnaire confirmed that respondents experienced a need for more mass media in their mother tongue. Of the 62 respondents, $48(77 \%)$ indicated that they would obtain more enjoyment from television if a channel were to be devoted to their mother tongue. Around $90 \%$ of respondents also indicated that there should be a newspaper in their mother tongue. This clearly demonstrates respondents' desire to expand the sphere of use and therefore also the functions of their language, from mainly a language of interaction at home to a language of public communication. This is supported by a significant indication from respondents that they wish their mother tongue to be used more extensively in education, with $85 \%$ of respondents indicating that they think their mother tongue should be used as medium of instruction for part of or the entire primary and secondary education.

This again confirms a desire to expand the functions of respondents' mother tongue. It also indicates an important attitudinal emphasis: respondents clearly value their mother tongue, despite the perceived advantages and status of an English-medium education.

The final attitudinal question, namely "What does it mean to you to communicate in your language" elicited responses that can be divided into two groups. The first group of responses centred on the idea that such communication creates a feeling of pride in and/or respect for the language. Cultural value therefore plays a role here, indicating that written language can have an important function as "a symbol of ethnic identity" (Verhoeven \& Durgunoğlu 1998: xi). The second group of responses indicated that respondents felt that communicating in your mother tongue allows you to express yourself effectively and in a nuanced way. Only about $8 \%$ of respondents indicated that they felt neutral about communication in their mother tongue.

The responses to this question also suggest that respondents regard issues related to status and acquisition as important.

The second part of the experiment, namely the comprehension questionnaire, yielded less clear information. This may be ascribed to a number of factors, such as the following: 
- The sample group was too small to yield any reliable quantitative data.

- The dialogue in the video, although containing languages such as isiZulu and Sesotho, is mainly in English, which introduced an undesirable variable, namely English proficiency.

- $\quad$ As a result of the fact that Tshivenda and Xitsonga are mainly used in verbal communication in informal contexts, respondents who saw the video with mother-tongue subtitles could not necessarily be expected to maintain the relatively high reading speed (160 words per minute) required to be able to read the subtitles.

- Approximately $25 \%$ of the respondents were functionally illiterate (no schooling, or less than four years of schooling).

- $\quad$ Finally, subtitled television is still not fully established in South Africa, with the result that not all respondents were familiar with the mode.

Nevertheless, the frequency tables for correct answers for the Tshivenda and Xitsonga groups do seem to indicate at least a slightly higher level of comprehension in the groups who did have access to subtitles, most notably in the case of the Xitsonga respondents.

Table 2: Percentage of comprehension questions answered correctly, per subgroup

\begin{tabular}{|l|l|l|}
\hline Language group & Subgroups & $\begin{array}{l}\text { Percentage of com- } \\
\text { prehension questions } \\
\text { answered correctly }\end{array}$ \\
\hline \multirow{3}{*}{ Tshivenda group } & Group 1: English subtitles & $51 \%$ \\
\cline { 2 - 3 } & Group 2: Tshivenda subtitles & $44 \%$ \\
\cline { 2 - 3 } & Group 3: No subtitles & $41 \%$ \\
\hline \multirow{3}{*}{ Xitsonga group } & Group 1: English subtitles & $29 \%$ \\
\cline { 2 - 3 } & Group 2: Xitsonga subtitles & $50 \%$ \\
\cline { 2 - 3 } & Group 3: No subtitles & $27 \%$ \\
\hline
\end{tabular}

The focus-group discussions that concluded the session confirmed the attitudinal data. In both language groups respondents who saw the video with mother-tongue subtitles indicated that the subtitles enabled them to grasp the meaning of the video more fully, primarily because it gave them access to those parts of the dialogue that were in languages they do not understand. More importantly, these respondents also consistently remarked on the fact that seeing their language represented on screen filled them with pride and gave them the feeling that their language is being recognised. Some respondents also indicated that illiterate viewers in their communities may be motivated to learn to read in order to be able to 'read' programmes they would otherwise not have access to. The groups who saw the video with English 
subtitles commented on the fact that they would like to see subtitles in their own languages since that would make them feel acknowledged and would also give speakers of these languages pride in their own languages. The groups who saw the video without subtitles also indicated that they would have preferred to see the video with mother-tongue subtitles. Some respondents said that subtitles in their language would allow the language to survive by being passed on to later generations. Some respondents admitted that they could not follow the languages used in the dialogue and that they only watched the pictures.

\section{Conclusion and further research possibilities}

The pilot study clearly suggests that a need exists among speakers of marginalised languages for their languages to be recognised, developed and expanded, so that these languages can fulfil higher-order functions. In addition, respondents clearly indicated that they felt that subtitles in their mother tongue would contribute to the recognition, development and expansion of their language.

As far as comprehension is concerned, the study does suggest that subtitles, either in the mother tongue or in English, have the potential to improve the accessibility and comprehension of audiovisual materials.

The pilot study has also emphasised that illiteracy is still a significant factor in South Africa, particularly in the rural areas where many of the marginalised languages are spoken. In terms of promoting multilingualism, literacy training through the introduction of intralingual or same-language subtitles (see Kothari 1999) may therefore be a higher priority than, for example, status and corpus planning, although these aspects of promoting multilingualism would also be served through intralingual subtitling. Intralingual subtitles should therefore be part of the strategy for the promotion of multilingualism through subtitling, together with interlingual subtitling.

The comprehension section of the experiment should be repeated in order to determine the statistical significance of the difference between groups who see a programme with mother-tongue subtitles and groups who see it without subtitles. Nevertheless, the findings of our attitudinal questions as well as the focus-group discussions provide sufficient evidence of the important role mother-tongue subtitles can play in terms of language status and acquisition towards establishing a truly multilingual country.

\section{Bibliography}

Allafrica.com (2005). "Icasa orders language quota change at SABC". www.allafrica.com/stories/200506140515.html. (last visited on 19 November 2007).

Barnett, Clive (2000). "Language equity and the politics of representation in South African media reform". Social Identities 6(1), 63-90.

Chomsky, Noam (1979). Language and Responsibility. London: Harvester. 
Cooper, Robert L (1989). Language Planning and Social Change. New York: Cambridge University Press.

Desai, Zubeida (1994). "Praat or speak but don't theta: on language rights in South Africa". David Barton (ed.) (1994). Sustaining Local Literacies. Clevedon: Multilingual Matters, 19-29.

Durgunoğlu, Aydin Y \& Verhoeven, Ludo (1998). "Epilogue: multilingualism and literacy development across different cultures”. Ludo Verhoeven \& Aydin Y Durgunoğlu (eds). Literacy Development in a Multilingual Context: Cross-cultural Perspectives. Mahwah: Lawrence Erlbaum, 289-298.

Erasmus, Mabel (2002). "Making multilingualism work in South Africa: the establishment of translation and interpreting services for local government". Eva Hung (ed.). Teaching Translation and Interpreting 4. Amsterdam: John Benjamins, 197-210.

Harare Declaration (1997). "Harare declaration: intergovernmental conference of ministers on language policy in Africa, Harare, 20-21 March 1997".

http://www.bisharat.net/Documents/Harare97Declaration.htm. (last visited on 19 November 2007).

Joubert, Jan (1999). "SABC sê te min geld is rede vir gebrek aan veeltaligheid". Beeld, 15 May.

Kothari, Brij (1999). "Literacy skill development for the millions of neo-literates in India, through television and popular songs".

http://www.globalknowledge.org/worldbank/ikd/current/0283.html. (last visited on 19 November 2007).

Kruger, Jan-Louis, Verhoef, Marlene M. \& Kotze, Haidee (2000). Subtitling in South Africa. Unpublished report: PanSALB.

Kruger, Jan-Louis \& Kruger, Helena C (2001). Subtitling in South Africa: Summary Report. PANSALB Occasional Papers 4. Pretoria: Pan SALB.

Kruger, Jan-Louis (2003). Training Subtitlers in South Africa. Unpublished report: PanSALB.

May, Stephen (2004). "Rethinking linguistic human rights: answering questions of identity, essentialism and mobility". Jane Freeland \& Donna Patrick (eds). Language Rights and Language Survival: Sociolinguistic and Sociocultural Perspectives. Manchester: St Jerome, 35-53.

Media Monitoring Project (2005). SABC Draft Licence Conditions Submission. Johannesburg: Unpublished report: Media Monitoring Project.

MISA-SA (2003). "Public broadcasting in South Africa: MISA comments on SABC's draft editorial policy". http://www.ifj.org/default.asp?index=1731\&Language=EN. (last visited on 19 November 2007).

PanSALB (2001). Guidelines for Language Planning and Policy Development: Language Use and Language Interaction in South Africa. PanSALB Occasional Papers 6. Pretoria: PanSALB.

SABC (2002). "SABC1 - frequently asked questions". http://www.sabctv.co.za/sabc1faqs. (last visited on 19 November 2007).

SABC (2005). "Language".

http://vcmstatic.sabc.co.za/VCMStaticProdStage/CORPORATE/SABC\%20Corporate/Doc ument/About\%20SABC/Legislative\%20\&\%20Regulatory\%20Organs/language.pdf. (last visited on 19 November 2007).

SABC (2006). Monitoring Report to ICASA. Unpublished report. SABC.

Sachs, Albie (1994). "Language rights in the new South African constitution". English Academy Review 11, 105-131.

South Africa (1996). The Constitution of the Republic of South Africa. Pretoria: Government Printer.

Statistics South Africa (2003). "Census 2001: Census in brief". http://www.statssa.gov.za/SpecialProjects/Census2001/HTML/CimBrief/CIB2001.pdf. (last visited on 19 November 2007).

Verhoef, Marlene (1998). "In pursuit of multilingualism in South Africa," Multilingua ("Aspects of Multilingualism in Post-apartheid South Africa," ed. Nknoko M. Kamwangamalu) 17 (23).

Verhoeven, Ludo \& Durgunoğlu, Aydin Y (eds) (1998). Literacy Development in a Multilingual Context: Cross-cultural Perspectives. Mahwah: Lawrence Erlbaum.

Webb, Vic (1996). "Language planning and politics in South Africa". International Journal for the Sociology of Language 118, 139-162. 
1 This research project was made possible by funding received from the Pan South African Language Board (PanSALB) in 2005. The project leader was Prof. MM Verhoef, director of the North-West University Language Directorate.

${ }^{2}$ See Verhoef (1998:181-96) on how the tension between symbolic and functional multilingualism affects language planning efforts in South Africa.

3 See Kruger, Verhoef and Kotze (2000), Kruger and Kruger (2001) and Kruger (2003).

4 See Desai (1994) for a more in-depth discussion of the concept of language rights, and its relationship with human rights. 